\section{Coming Events}

Due to COVID-19, please check to see if the listed events have been postponed or cancelled.

\section{1}

Neuroscience 2021 (Virtual)

November 3-7, 2021 (Preview)

November 8-11, 2021 (Meeting)

Virtual

http://www.sfn.org/meetings/neuroscience-2021

flowcytometryUK 2021 (formerly One

Day flowcytometryUK)

November 17-18, 2021

Virtual

www.rms.org.uk/rms-event-calendar/2021-

events/flowcytometryuk-2021.htm

2021 MRS Fall Meeting \& Exhibit (Hybrid)

November 29-December 2, 2021 (in person)

December 6-8, 2021 (virtual)

Boston, MA and Virtual

www.mrs.org/fall2021

Cell Bio Virtual 2021

December 1-10, 2021

Virtual

https://www.ascb.org/cellbio2021

\section{2}

BPS2022: 66th Biophysical Society

Annual Meeting

February 19-23, 2022

San Francisco, CA

https://www.biophysics.org/2022meeting\#

ABRF 2022 Annual Meeting

March 27-30, 2022

Palm Springs, CA

https://www.abrf.org/abrf-annual-meeting

Experimental Biology 2022

April 2-5, 2022

Philadelphia, PA

https://www.experimentalbiology.org

7th International Conference on

Nanomaterials, Nanodevices,

Fabrication and Characterization (ICNNFC'22)

April 4-6, 2022

Hybrid

Lisbon, Portugal and Virtual

https://icnnfc.com

Microscopy \& Microanalysis 2022

July 31-August 4, 2022

Portland, OR

www.microscopy.org/events/future.cfm

\section{3}

Microscopy \& Microanalysis 2023

July 24-28, 2023

Minneapolis, MN

www.microscopy.org/events/future.cfm

2024

Microscopy \& Microanalysis 2024

July 28-August 1, 2024

Cleveland, $\mathrm{OH}$

www.microscopy.org/events/future.cfm

\title{
My, What Hard Teeth You Have!
}

\author{
Stephen W. Carmichael \\ Mayo Clinic, Rochester, MN 55905 \\ carmichael.stephen@mayo.edu
}

The chiton is a marine mollusk that feeds primarily by scraping algae off of rocks. This requires very hard, sharp teeth that can withstand considerable abrasive forces. Furthermore, the teeth are mounted on an apparatus that is flexible, yet strong, to facilitate the sweeping motions of the teeth during feeding. An elegant study by Linus Stegbauer, Paul Smeets, Robert Free, Shay Wallace, Mark Hersam, Esen Alp, and Derk Joester addressed the significant challenges involved in engineering structures that bridge between elements with disparate mechanical properties. They studied the radula, the scraping organ, of the chiton Cryptochiton stelleri [1]. This coast-dwelling mollusk is commonly called the gumboot chiton, suggesting that it is not tasty to eat; it is also nicknamed "the wandering meatloaf" because of its large (more than $30 \mathrm{~cm}$ long), oval, reddish-brown body. However, beneath this modest exterior is concealed a mouth with a tongue-like radula with several rows of hard, sharp teeth (Figure 1). The radula is about $5 \mathrm{~cm}$ long and shows all stages of tooth development. These include the initial organic scaffold (stage I), infiltration with the iron-containing compound ferrihydrite (stage II), conversion to the iron-rich compound magnetite (stage III), mineralization of the core (stage IV), and mature teeth (stage V). The progressive mineralization of teeth in the radula from the base (stage I) of the radula to the apex (stage V) was the main emphasis of this study.

The tooth head is comprised of a highly mineralized cusp with exceptional hardness, which is among the hardest mineralized tissues known in nature. This hard cusp is also notable for its wear resistance and self-sharpening properties. The cusp is mounted on a projection called the stylus that anchors the tooth on the thin and flexible radula membrane; prior to this investigation, the stylus was considered to be unmineralized. A virtual section of a tooth head and upper stylus, generated from a $3 \mathrm{D}$ reconstruction of the normalized linear attenuation coefficient (LAC) as determined by synchrotron microcomputed tomography, shows the LAC is highest for the outer layer of the head, intermediate for the underlying core of the tooth, and rather low in the stylus (Figure 2). This reflects that the outer layer contains magnetite, the core contains amorphous ferric phosphate (AFP), and the stylus has less iron.

In addition to microcomputed tomography, Stegbauer et al. also used transmission and scanning electron microscopy, sometimes combined with energy dispersive

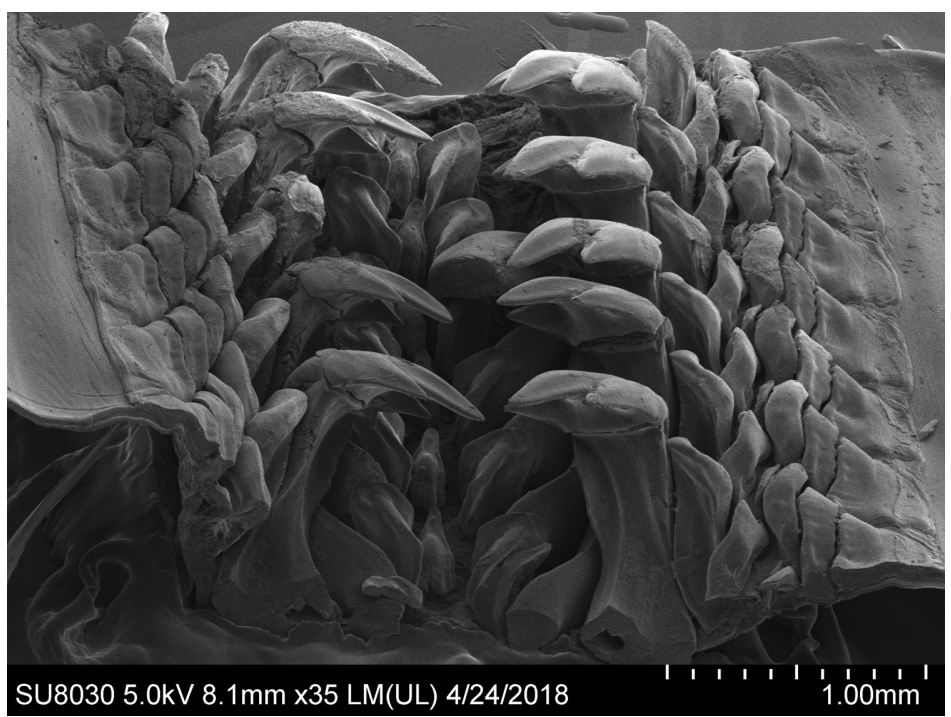

Figure 1: Scanning electron microscope image of the anterior end of the radula with mature teeth. Credit: Northwestern University. 


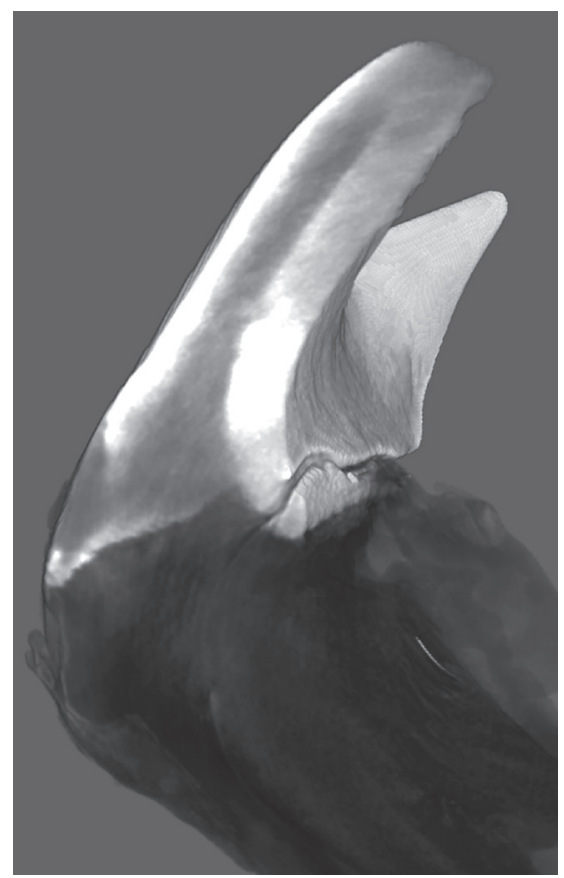

Figure 2: Rendering of a virtual section of a single tooth head and upper stylus, generated from a 3D reconstruction as determined by synchrotron microcomputer tomography. Credit: Northwestern University.

X-ray spectroscopy, to visualize structural features of the tooth. Given the complex shape and small size of chiton teeth and the extraordinary rich chemistry of iron, they also used the newly developed technique of synchrotron Mössbauer spectroscopy for its high spatial resolution and the deep chemical insights this technique offers.

Briefly, Stegbauer et al. are confident that they identified nanoparticles of santabarbaraite (SBB), a rare amorphous ferric hydroxyphosphate, in the stylus. SBB was only discovered in the year 2000, and until this study it has only been observed in rocks! It was suggested that these particles could toughen the teeth without adding much weight. The distribution of AFP and SBB within the stylus apparently allows the hardness and stiffness to vary by at least a factor of two over a distance of a few hundred microns. This addresses the significant challenge of engineering structures that bridge between elements with disparate mechanical properties.

Finally, to demonstrate the usefulness of this discovery, Stegbauer et al. designed bio-inspired inks for 3D printing. The results demonstrated some of the impressive mechanical properties they found in the chiton tooth, and they anticipate further improvements will be straightforward. These inks can be used to make strong, lightweight materials that vary in hardness and stiffness, and which have potential applications in robotics that mimic biologic structures. This is the emerging field of "soft robotics," and Stegbauer et al. appear to have made a significant contribution!

\section{Reference}

[1] L Stegbauer et al., PNAS 118 (2021) e2020160118 https:// doi.org/10.1073/pnas.2020160118.

[2] The author gratefully acknowledges Dr. Derk Joester for reviewing this article.

\section{Finally! Full-Size Performance In a Tabletop Package}
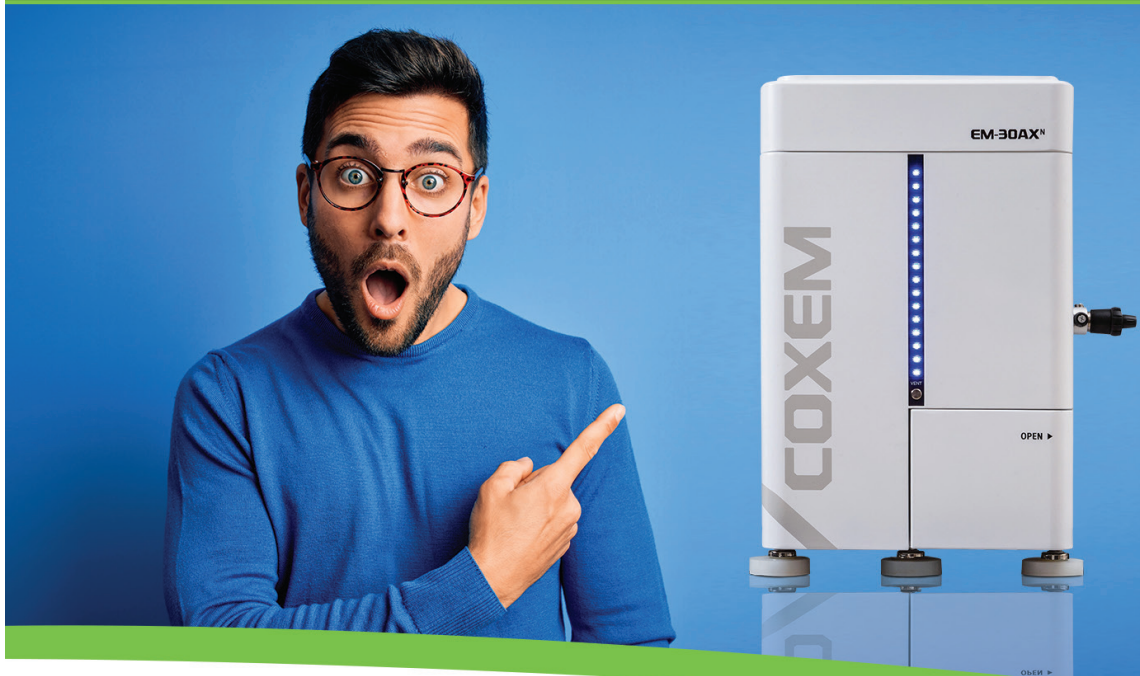

EM-30
$\begin{gathered}\text { Table } \\ \text { Top }\end{gathered}$ Moor
SE and BSE detectors
High and Low Vacuum
Dry pump option
Navigation camera
Adjustable objective apertures
EDS system
Auxiliary ports
Image program (mosaic)
3D imaging software
Small footprint
Under \$100k

\section{All the features you want without the high cost!}

At COXEM, we believe that microscopy doesn't have to be complicated or expensive. Our tabletop

microscopes deliver the performance and features advanced users expect, at a price that entry-level users

can afford. Call your local agent to arrange a demonstration, or visit our website for more information.

www.coxem.com / ElementPi (US distributor) www.elementpi.com

COXEM 